\title{
Arbor
}

\section{Manuel Martínez de la Escalera, ciencia y aventura en Oriente}

\author{
Santos Casado
}

Arbor CLXXX, 711-712 (Marzo-Abril 2005), 843-858 pp.

Manuel Martínez de la Escalera fue el expedicionario más destacado entre los naturalistas españoles de las décadas en torno al cambio de siglo. Su dedicación a la entomología, especialmente a los coleópteros, le llevó a organizar sendas expediciones, financiadas por un coleccionista francés, a Asia Menor y Siria en 1898 y a Persia en 1899. Lo aventurero de sus viajes a Oriente, subrayado por la penuria material con que se realizaron, marcó la incorporación de Escalera al imaginario colectivo de la reducida comunidad naturalista española, con una intensidad que contrasta con el olvido de los medios académicos oficiales y de la posterior historiografía de la ciencia.

El 7 de junio de 1899 Ignacio Bolívar informaba en la reunión mensual de la Sociedad Española de Historia Natural de las últimas novedades llegadas de la expedición científica que por esas fechas realizaba a través de Mesopotamia y Persia uno de sus miembros, el entomólogo Manuel Martínez de la Escalera. Las noticias eran buenas. Tras haber cruzado en caravana desde Bagdag todo el territorio del actual Irak, los expedicionarios habían llegado sanos y salvos a las excavaciones arqueológicas de Susa, donde habían sido atendidos por los investigadores franceses que allí trabajaban. Se disponían ahora a emprender la parte más difícil y azarosa de su viaje, que había de llevarles por el interior de la alta cordillera de los Zagros hasta la ciudad persa de Ispahan, 
en el centro del actual Irán. Se esperaban de esta expedición interesantes resultados científicos en forma de ejemplares de insectos, plantas y otros organismos nuevos o poco conocidos, y ello a pesar de que, como se lamentaba Bolívar, «nuestro Gobierno no les haya facilitado los medios más indispensables para realizarla» ${ }^{1}$.

En el umbral del nuevo siglo, la expedición entomológica de Escalera a Oriente era, desde luego, uno caso totalmente atípico en el panorama de las ciencias naturales en España. No era solo que en aquellos años los españoles siguieran estando prácticamente ausentes de los grandes proyectos expedicionarios que otras naciones habían impulsado, al ritmo de la expansión colonial, durante todo el siglo diecinueve, incluidas exploraciones geográficas, campañas oceanográficas y prospecciones geológicas, botánicas y zoológicas ${ }^{2}$. Es que el propio territorio español estaba siendo explorado por naturalistas extranjeros, que encontraban en la Península una tierra de promisión, pródiga en novedades por estar mucho menos estudiada que sus países de origen.

De ahí la singularidad de los viajes de Escalera a Oriente en los años del cambio de siglo. $Y$, desde el punto de vista de la autoimagen de las comunidades científicas, objeto de reciente atención historiográfica ${ }^{3}$, de ahí también la especial huella que dejaron aquellas expediciones en la memoria colectiva de la reducida pero animosa comunidad de naturalistas españoles. "La cosecha de plantas y animales obtenida", se afirmaba en un estudio histórico sobre el Museo de Ciencias Naturales y sus colecciones hecha por uno de sus investigadores, «fue por demás abundante y de un interés extraordinario por tratarse de una región poco o nada explorada» ${ }^{4}$. "Puede decirse que es casi el único entomólogo español que ha hecho viajes de importancia y cazas intensas en países extranjeros", reconocía un prestigioso colega ya bien entrado el siglo veinte ${ }^{5}$. Por todo ello no cabe considerar sino como estridente anomalía, reflejo de la endeble implantación que la historiografía de la ciencia ha tenido demasiado tiempo en la cultura española, el que Escalera no haya contado hasta hace muy poco con un solo estudio biográfico o histórico que recopilase al menos lo esencial de su dilatada y productiva trayectoria científica. Téngase en cuenta que Escalera, dejando aparte la aureola que le confirió su perfil aventurero y tomando una referencia cuantitativamente objetivable, fue el autor más prolífico, con más de un centenar de trabajos, de cuantos publicaron hasta la guerra de 1936 en el Boletín de la Real Sociedad Española de Historia Natural, la revista científica de referencia para los naturalistas de la época ${ }^{6}$. 


\section{Manuel Martínez de la Escalera, ciencia y aventura en Oriente}

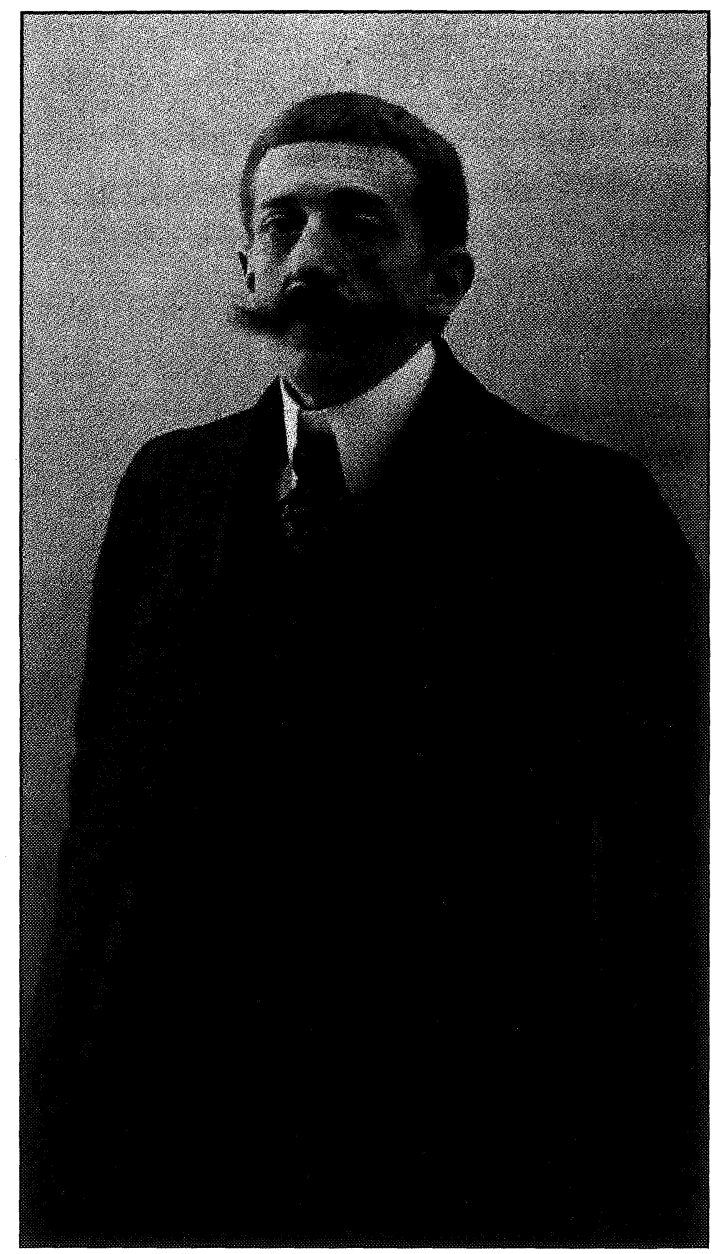

Figura 1. Retrato fotográfico de Manuel Martínez de la Escalera.

Archivo del Museo Nacional de Ciencias Naturales. Madrid

A remediar provisionalmente esta situación de desconocimiento historiográfico vino el artículo que sobre Escalera apareció en 1998 y del que este trabajo es continuación ${ }^{7}$. Aquel primer esbozo, de donde se toman, si no se indica otra cosa, los datos biográficos que siguen, se basó fundamentalmente en los papeles que don Eugenio Morales Agacino tuvo la amabilidad de facilitarme, papeles que había recopilado muchos años antes con la intención, que no llegó a cumplir, de componer él mismo un escrito dedicado al que había sido uno de sus maestros. Eugenio Morales falleció en Madrid en 2002. Deseo dar aquí nuevamente expresión pública de mi agradecimiento. 


\section{Entomólogo vocacional}

Manuel Martínez de la Escalera y Pérez de Rozas, pues tal era su nombre completo, aunque casi siempre firmó sus trabajos abreviadamente como Manuel M. de la Escalera, nació el 18 de diciembre de 1867 en San Sebastián, lugar donde estaba destinado su padre, aduanero de profesión, cuyo origen familiar provenía sin embargo de la comarca de Los Cameros, en la actual comunidad de La Rioja.

Para entender su posterior trayectoria profesional como entomólogo es preciso advertir, en primer lugar, las peculiaridades que históricamente ha revestido el estudio de los insectos, cultivado no solo por científicos profesionales en universidades y museos sino también, y muchas veces sobre todo, por aficionados al coleccionismo entomológico, fenómeno de notable alcance social y cultural en algunos países occidentales ${ }^{8}$, que también alcanzó en España, aunque de modo mucho más modesto, algún desarrollo. El de Escalera fue el caso del entomólogo vocacional, que sintió desde muy joven la afición a la colección y el estudio de los insectos, y que de hecho trató de hacer de ello su dedicación profesional. Dado que su titulación académica no le permitía en principio aspirar a profesionalizarse como científico, pues había seguido por decisión paterna los estudios de Derecho, buscó en el mundo de los aficionados y el coleccionismo posibilidades para ejercer actividades remuneradas que le permitieran cultivar su pasión por los insectos. Así, comenzó a recolectar insectos por toda la Península, intercambiándolos con otros coleccionistas y vendiendo lotes a casas comerciales y museos europeos. Su especialidad eran los coleópteros y, entre ellos, algunos de los grupos más característicos y diversificados en la Península, como los tenebriónidos o los cerambícidos, de los que fue reuniendo colecciones extraordinariamente completas.

Fue hacia 1890, una vez terminados los estudios seguidos por imposición familiar, cuando Escalera orientó definitivamente sus aspiraciones personales y profesionales, al tiempo que daba otro paso decisivo en su vida, al casarse, por amor, con Emma Goróstegui, una joven sordomuda y al parecer muy hermosa. El matrimonio tuvo tres hijos, una mujer y dos varones. Para ganarse la vida, en esos años se instaló y montó una vaquería en la localidad madrileña de Villaviciosa de Odón, sin dejar por ello de cultivar sus aficiones y negocios entomológicos. Estos últimos iban adquiriendo al tiempo mayor solvencia científica, pues el joven Escalera había entrado en contacto con los entomólogos del Museo de Ciencias Naturales y la Sociedad Española de Historia Natural, de la cual él mismo era miembro desde 1889. Fue seguramente Ignacio Bolívar, con quien co- 
menzaba este relato, el que le llevó a la Sociedad de Historia Natural. Bolívar no solo era un especialista en ortópteros de enorme prestigio sino también una de las figuras más influyentes en la comunidad científica. Siempre atento a fomentar las vocaciones de nuevos valores científicos, y Escalera sin duda lo era, Bolívar fue desde entonces una de las referencias clave en su trayectoria profesional.

Pero había de trascurrir casi una década para que el amateur Escalera, al tiempo que amasaba una excepcional colección, especializada en escarabajos o coleópteros, adquiriese la suficiente competencia científica como para convertirse también en autor de trabajos de investigación, siendo el primero de ellos, notas y comunicaciones breves aparte, una revisión de los coleópteros cavernícolas del género Bathyscia, que ultimó en 1898, aunque no apareció publicada hasta $1900^{9}$. Y precisamente en 1898, en ese momento de incipiente madurez científica, Escalera se vio forzado por problemas económicos a vender por 3000 francos su magnífica colección al francés René Oberthür, poseedor a su vez de una de las mejores colecciones coleopterológicas de Europa ${ }^{10}$. De la dimensión alcanzada, al menos en ciertos países europeos, por el fenómeno coleccionista, según más arriba se advirtió, es muestra el que Oberthür no solo desembolsase esa considerable suma sino que además, por 1800 francos más, contratase a Escalera como colector para realizar una expedición entomólogica por los montes Amanus, en el norte de Siria, y la cordillera del Taurus, en el sur de Anatolia, con el fin de aumentar sus fondos con nuevas o raras especies. Fue así como Escalera inició su primera aventura en Oriente.

\section{El viaje a Siria y Asia Menor}

El 5 de abril salía Escalera de Madrid hacia Marsella, donde tomó un vapor con destino a Alejandreta o Iskenderun, ciudad situada en lo que entonces se consideraba el norte del territorio de Siria, aún parte de un agonizante Imperio Otomano, y hoy es el extremo meridional de Turquía. De la primera parte del itinerario y los resultados de aquel viaje dejó Escalera un breve relato en una notas manuscritas ${ }^{11}$ que merece la pena trascribir, lo que se hace a continuación, manteniendo sin enmiendas la ortografía original.

En Abril de 1898 embarcaba yo en Marsella con rumbo al Asia Menor para hacer colecciones entomológicas con el apoyo moral y metálico de Mr. René Oberthur de Rennes: me había avanzado sobre el 1er lote de mis cazas á hacer de Coleópteros 2.000 francos: la expedición era fácil, tres meses de campaña en los montes Amanus y parte occidental 


\section{Santos Casado}

del Taurus, región muy rica en Coleópteros y poco estudiada con excepción del Akbés donde había cazado anteriormente el P. Davis Lazarista y Mr. Delagrange por cuenta del mismo Oberthur y un grupo de entomólogos franceses: el viaje de ida y vuelta á Alejandreta en $3 .^{a}$ costaba entonces menos de 400 francos; de suerte que con algo que añadí de mi peculio al embarcar contaba con 2.600 francos. Así es que despues de tocar en Nápoles y en el Pireo (Atenas) desembarqué en Smyrna para aprovechar los días que empleaba el vapor de las «Messageries» en ir a Constantinopla, para volviendo á tocar en Smyrma seguir por Adana, Alejandreta, Beyruth, Jaffa, etc. en viaje de retorno.

En los 5 días que tenía de márgen para reembarcar, opté por tomar el ferrocarril que por Aydín hacia el interior me llevó cerca de Kónia á la serrería de Paul Bradiz, en la vertiente N. del Taurus occidental cuya otra falda contornea el Golfo de Adana: el encargado de la empresa maderera era pariente del intérprete armenio que me había proporcionado el cónsul honorario de España en Smyrma, comerciante austriaco á la sazón: el pariente del intérprete debía alojamos según carta que recibiría de sus principales.

Toda la llanada de Konia como nuestra estepa manchega es una altiplanicie pantanosa a trechos donde se suman y reunen las aguas del $\mathrm{N}$. del Taurus cadena aún vestida entonces de cedros y pinos; en las cercanías de la serrería en los $1 .^{\text {os }}$ contrafuertes de la cadena estaba esta desnuda casi por completo; la estacion muy atrasada aún por ser region fría me proporcionó pocas especies, 3 de Dorcadion de medianas alturas y por ello de gran área de dispersión, algunos Carábidos y pocos Tenebriónidos, y nada más; la localidad no es recomendable y el hospedaje para un europeo dejaba mucho que desear; de suerte que al $2^{\circ}$ día tomé el tren de vuelta y me detuve en Aydín, donde en unas horas hice amplia cosecha, más de 500 ejemplares en una cincuentena de especies de las que alguna rara: había en Aydín una colonia israelita muy numerosa, que habla español arcaico; por las calles, como en viaje posterior pude oir en Constantinopla, vendedores ambulantes, vocéan unos rosquetes como nuestros «panecillos del Santo" con el pregón en castellano de "frescóóó Pan de Españan: siempre es agradable el oir en tierra extraña la lengua Pátria y aún de labios heréticos más porque demuestra la persistencia del vínculo que no pudo romper la persecucion religiosa.

De regreso a Esmirna, sigue viaje a Alejandreta, a donde llega el 25 de abril. Allí se inicia su verdadera expedición, en la que recorrerá una extensa región montañosa del sureste de Anatolia. Tras recolectar en los alrededores de la ciudad, a primeros de mayo emprende ruta por los mon- 
tes Amanus, "poblados de cedros, pinos y encinas» ${ }^{12}$, dirigiéndose hacia la misión católica situada en Akbés, donde es acogido amigablemente por los padres lazaristas que la regentan. La mayor parte del mes de mayo la pasó en la comarca de Ekbez, prospectando medios de llanura y montaña donde rápidamente enriqueció sus capturas con centenares de diferentes especies de coleópteros y otros grupos.

En junio se adentra hacia el norte en los montes Taurus. Por Islahiye y la comarca de Giaour llega a la ciudad de Maras o Marasche. Su periplo le permite irse encontrando con diferentes tipos de fauna y seguir enriqueciendo sus capturas. Continúa internándose en el nudo montañoso que forma esta región de Turquía, prospecta varias cimas y llega finalmente a mediados de julio a Zeytun y a Bimbogha Dagi, cumbre de casi 3000 metros, desde donde inicia el regreso. Había recorrido centenares de kilómetros a pie con la sola ayuda de su guía, un kurdo llamado Bekir, y una caballería de carga, durmiendo al raso con apenas unas mantas y un mosquitero o en las tiendas de los nómadas que encontraban. «Los naturales, así turcos como turkmenes, tcherques y armenios, me han acogido bien por regla general», contará Escalera a su vuelta, insistiendo en que "el fanatismo musulmán no es tan grande como se cree; yo he hecho buenas amistades con algunos» ${ }^{13}$.

En la madrugada del 19 de julio llegaba de nuevo a Maras, dando fin a casi tres meses de expedición ininterrumpida. Había reunido 20,000 ejemplares de casi dos millares de diferentes especies.

\section{El viaje a Persia}

Cuando en agosto de 1898 hubo regresado a España después de su periplo oriental, a Escalera le faltó tiempo para organizar una nueva expedición. Mediante un nuevo contrato con Oberthür, esta vez por 4500 francos, y acompañado ahora por su hermano Fernando, quien iba a encargarse de reunir colecciones botánicas, Escalera inició en enero de 1899 un viaje mucho más ambicioso con destino a los montes Zagros, en el cuadrante suroccidental de Persia, actual Irán, donde había de explorar regiones prácticamente desconocidas para los entomólogos. Pero en vez de acceder directamente por mar por la ruta del canal de Suez y el golfo Pérsico, viaje muy caro para sus modestos recursos, se dirigió de nuevo a Alejandreta, donde organizó una caravana terrestre para atravesar Siria, recorrer luego toda Mesopotamia, en el actual Irak, siguiendo el Eúfrates hasta la altura de Bagdag y más tarde el Tigris hasta 
Amara, y llegar finalmente a la frontera occidental de Persia. Atravesaron luego el territorio del belicoso grupo de los Beni-Laam, cuyo jefe les dió un salvoconducto que más adelante había de serle muy útil en sucesivos territorios. Y así llegaron a las excavaciones de Susa, regentadas por arqueólogos franceses que les acogieron cordialmente, desde donde los hermanos Escalera enviaron a sus compañeros científicos de Madrid las noticias de su viaje citadas al comienzo de este relato.

Pero quedaba todavía lo más interesante y lo más duro de la expedición, atravesar los abruptos montes Bakhtiari, parte de la alta cordillera de los Zagros, hasta la legendaria ciudad persa de Ispahan. Esta última etapa supuso cinco meses de ruta de montaña llena de dificultades, tal como luego relató el propio Escalera cuando estuvo de vuelta entre sus compañeros de la Sociedad Española de Historia Natural, de cuyas actas están tomados los siguientes pasajes ${ }^{14}$.

De Susa fuimos por Dizfoul á Schouster, ya sobre el Karoum, y de esta villa, hoy ruinosa, remontando el río, nos internamos en los montes Bakhtyari, parte de los Zagros, en la cual viven los Loris y Bakhtyaries, de pésima fama, según todos los autores. No son buenos á decir verdad, pero no tan feroces como se les pinta, pues nosotros hemos vivido entre esas hordas cuatro meses sin graves dificultades [...] Son los montes Bakhtyari enorme cadena de montañas que, en pliegues muy juntos y paralelos, vienen del NO. desgajados del núcleo del Ararat; sirve el sistema, como es sabido, de barrera á la meseta pérsica, donde se asienta Ispahan: con alturas variables, la de sus picos oscila entre 3.000 y $3.500 \mathrm{~m}$., descollando algunos, como el Zerde-Khou y Khoudená, que pasan de los 4.000: los valles entre estos pliegues son muy estrechos y abruptos, por los cuales corren torrentosos los arroyos que forman el Diz y el Karoum [...]

Cretáceo todo el sistema, con nieves perpetuas el Khon-Sefid y Zerde-Khou, casi en la línea recta de Schouster á Ispahan, están pobladas en sus macizos centrales de encinas y muy escasa vegetación herbácea, por la sequía extrema de toda la zona [...] Flora y fauna, si no ricas, son de verdadero interés y muy localizadas; naturalmente, participan de lo conocido del Caúcaso, Armenia y Mesopotamia; como curiosidad debo citar una Adesmia (coleóptero), abundantísima á los $3.300 \mathrm{~m}$., en el Khou-Sefid [...]

El total de materiales recogidos asciende á la cantidad de 3.000 especies en Zoología y Botánica, cuya suma, al parecer corta, no lo es, teniendo en cuenta la pobreza de la región [...] No hemos podido reunir nada de tamaño; así de reptiles sólo hemos conservado pequeños lacértidos, y de mamíferos poco más de una docena de especies de cor- 
ta talla, roedores y quirópteros, porque requiere una expedición organizada al servicio de las Ciencias naturales, recursos pecuniarios con los cuales desgraciadamente no contábamos; en el caso anterior no nos ha detenido el gasto de algunos litros más de alcohol, sino la imposibilidad de transportarlo por falta de bagajes y personal que no podíamos sostener; aun así, en Amarah hube de comprar cinco caballos, de los cuales, al llegar a Ispahan, cinco meses después, sólo nos quedaba uno: perdidos, robados y despeñados los restantes.

$\mathrm{Al}$ terminar agosto llegan por fin a Ispahan y en septiembre emprenden el camino de regreso, cruzando de nuevo la cordillera por una vía algo más meridional, y siguen luego ruta hacia el sur hasta ganar la costa por Basora. En noviembre se embarcan para Bombay, desde donde pueden tomar un barco de regreso a Europa.

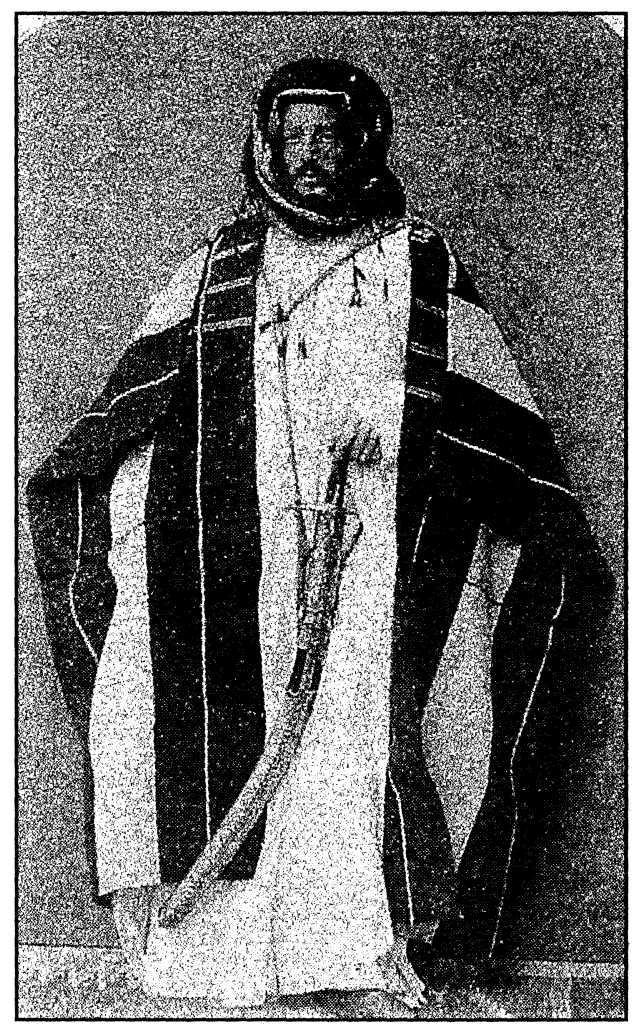

FIGURA 2. Escalera se hizo tomar esta fotografía, ataviado a la usanza local, a su paso por Alepo en 1899. Archivo del Museo Nacional de Ciencias Naturales, Madrid 
Fue un año de viaje en condiciones de extrema dureza, hasta el punto de dejar muy quebrantada la salud de Fernando, que muere a los pocos meses de llegar a España. Fue también la confirmación de la talla expedicionaria y naturalista de Manuel Martínez de la Escalera, quien años después recordaba la escasez de medios con que hubo de acometer aquella empresa. Fue una expedición, decía, «realizada pobremente como todas las que me ha cabido la honra de realizar y orgullosamente lo digo, siempre cabeza de raton y dueño de mis actos» ${ }^{15}$.

\section{Naturalista viajero}

El viaje, la expedición y la lejanía fueron desde entonces las señas distintivas de Escalera como naturalista y las que más y mejor lo singularizaron en la comunidad científica española de su época, sin desconocer su enorme producción taxonómica, centrada básicamente en los coleópteros y plasmada en numerosísimas publicaciones y en centenares de nuevas especies y formas descritas. Tras regresar de su segundo y gran viaje a Oriente aún iba a organizar por su cuenta un tercero en 1902, en el que regresó a las regiones de Asia Menor que había visitado en su primer periplo. Mientras tanto, desde 1901, inicia sus viajes a África, primero a la actual Guinea Ecuatorial y luego a Marruecos, que acabará siendo el teatro central de sus operaciones durante gran parte del resto de su vida. Esta etapa, a diferencia de la anterior, se inscribió en proyectos organizados por corporaciones científicas y apoyados, por modestamente que fuera, desde el Estado, en un caso más de típica combinación de ciencia y acción colonial ${ }^{16}$. Se trató de las expediciones promovidas o apoyadas desde la Comisión de Límites de los Territorios Continentales del Golfo de Biafra, la Comisión de Fauna y Flora de las Posesiones Españolas de África y, sobre todo, la Comisión de Estudios del Noroeste de África, creada en 1905 con el impulso de la Real Sociedad Española de Historia Natural y el patrocinio del Gobierno. Desde esta última fecha serán múltiples, y no pueden ser detallados aquí, sus viajes y trabajos en Marruecos, desarrollados a lo largo de un periodo muy complicado para la presencia colonial europea en el norte de África, en el que no faltaron situaciones de violencia y conflicto ${ }^{17}$. De hecho parece que la labor de Escalera revistió un doble carácter, pues unió a sus recolecciones e investigaciones científicas otras misiones de información como agente al servicio del Ministerio de Estado. La mayor parte de sus publicacio- 
nes de estos años se referirán también a la fauna marroquí, siendo la más relevante Los Coleópteros de Marruecos, un libro en el que Escalera ordenó toda la información disponible hasta la fecha sobre este amplísimo grupo y describió más de doscientas nuevas especies halladas por él ${ }^{18}$.

$\mathrm{Y}$, sin embargo, fueron sus dos primeras aventuras en Oriente las que quedaron en su propia memoria y en la imaginación colectiva de los naturalistas españoles como hazañas singulares, revestidas de un aureola entre heroica y quijotesca. La relegada situación por la que atravesaba España en el concierto mundial de las naciones, cruelmente subrayada en los años en que Escalera realizó sus dos primeros viajes, 1898 y 1899 , por el llamado desastre del 98, y el modo dramático en que todo ello fue vivido por la opinión pública, prestaban retrospectivamente a sus expediciones entomológicas en Asia Menor y Persia un especial valor simbólico. Así se aprecia en la reivindicación nacionalista escrita por Escalera años después a propósito de sí mismo y de algunos otros viajeros españoles en Oriente, integrantes de una nómina que, como muestra este volumen a lo largo del resto de artículos que lo componen, fue quizá no muy larga pero sí intensa ${ }^{19}$.

[...] no es que niegue á los yankees el mérito de haber filmado magistralmente escenas vividas y reales sin trucos, lo que sí niego es que hayan sido los primeros en sorprender y vivir esas escenas, ni yo tampoco [en 1899], porque 2 años antes Mr. de Morgan que hacía excavaciones en Susa había ido a Ispahan por la misma ruta, y poco antes D. Jaime de Borbón, españolísimo y buen viajero asiático había hecho lo propio y aun antes Rivadeneira hácia el 70 bajó el Eufrates, visitó Bagdag, y el Tigris y Schuster y remontó el Karum y llegó á Ispahan con los Baktiaris; esto era en los tiempos heroicos sin autos, ni aeroplanos, ni cinematógrafo pero ocurría lo mismo que vais á ver, desplazándose penosa pero animosamente.

Las referencias a los «yankees» y al «cinematógrafo» en estas notas retrospectivas, que por lo que ahora mismo se verá debieron de ser redactadas no antes de mediados los años veinte, aluden sin duda al célebre film norteamericano Grass, realizado en 1925 por los cineastas Merian C. Cooper y Ernest B. Schoedsack en colaboración con la periodista Marguerite Harrison, y considerado desde entonces uno de los títulos clásicos del «cine etnográfico» ${ }^{20}$. En Grass se documentaba en términos de epopeya primitiva la asombrosa migración anual de los bakhtiari y sus ganados hacia los pastos de los altos valles, atravesando el caudaloso río Karun y ascendiendo peligrosos pasos de alta montaña. Eran las mismas 
gentes con las que Escalera había convivido un cuarto de siglo antes, y la misma ruta que él había seguido a través de la cordillera de los Zagros. De ahí que su comentario a la película esté basado en la autoridad de la experiencia adquirida de primera mano cuando llevó su expedición «por los mismos caminos que ahora veréis»" 21 .He aquí esplicado [sic] así en breves palabras la razon de este éxodo anual de tribus y ganados; en comienzos de Mayo los llanos del Kuristan han dado sus cosechas, la hierba esta agotada por el bestiaje si antes la langosta no arrasó mieses y pastos y por los dos ó tres pasos unicamente practicables hay que cruzar penosamente esas cadenas paralelas de los Zagros tajadas por ríos torrenciales ascendiendo de los llanos atrasados del Arabistan y el Kuristan casi al nivel del mar por escalones sucesivos de $1.000,2.000$ y 3.000 metros para encontrar los pastos frescos de las faldas orientales» ${ }^{22}$.

El prestigio que así ganó entre sus colegas nunca se tradujo, sin embargo, en una estabilidad profesional para su dedicación a la entomología. Aunque, como ya se dijo, su doble preparación como explorador y naturalista le convirtió en una pieza clave de los proyectos expedicionarios a Marruecos y el golfo de Guinea impulsados desde instancias oficiales durante el primer tercio del siglo veinte, Escalera no pudo consolidar profesionalmente su vinculación al Museo Nacional de Ciencias Naturales, el centro de referencia para la investigación entomológica. El no tener una titulación universitaria adecuada supuso, en el contexto español, un obstáculo insalvable frente a la rígidez institucional del sistema académico. De estas rigideces se quejaba en 1915 Ignacio Bolívar, por entonces Director del Museo y cabeza visible de los entomólogos y aun del conjunto de los naturalistas españoles, cuando argumentaba que la subordinación de su centro a la universidad había acelerado su decadencia, «pues exigiendo los Reglamentos fuesen Jefes de las Secciones los respectivos Catedráticos de la Facultad, se impedía encomendar aquellos servicios a otras personas de reconocida competencia» ${ }^{23}$. Pero, incluso tras independizarse institucionalmente el Museo en 1910, las posibilidades de incorporar a elementos como Escalera en puestos acordes con su valía siguieron escaseando. Solo en 1932 pudo por fin regularizarse en parte su situación al obtener una plaza en el Museo como Entomólogo Agregado, puesto de todos modos inferior en rango al de otros especialistas que allí trabajaban como investigadores y responsables de las diversas secciones. En 1933 sufrió un accidente, al ser atropellado por un tranvía, de resultas del cual hubo de usar muletas el resto de su vida, lo cual no le impidió, cuando ya había cumplido los sesentaicinco años, seguir viajando y colectando insectos. 
Manuel Martínez de la Escalera, ciencia y aventura en Oriente

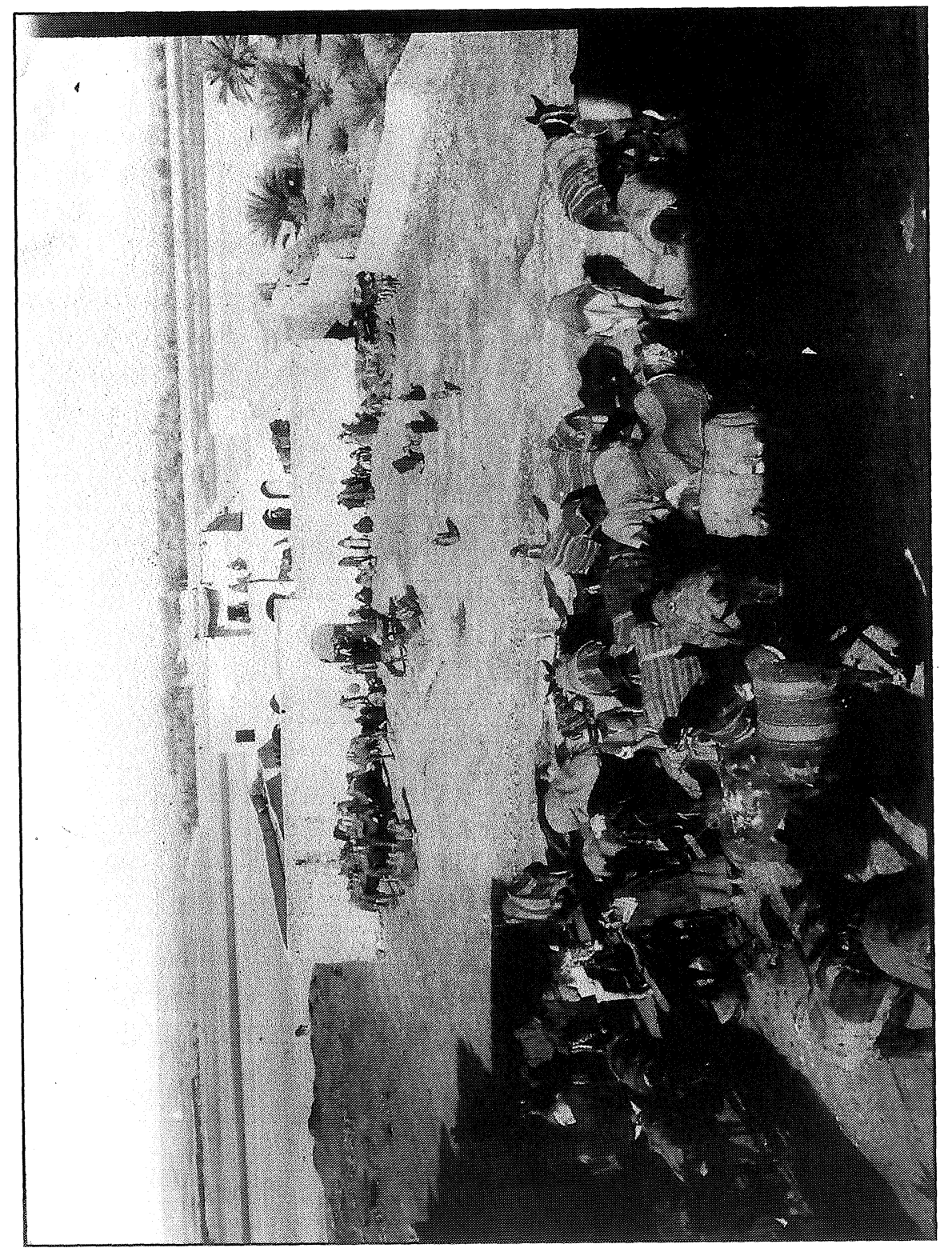

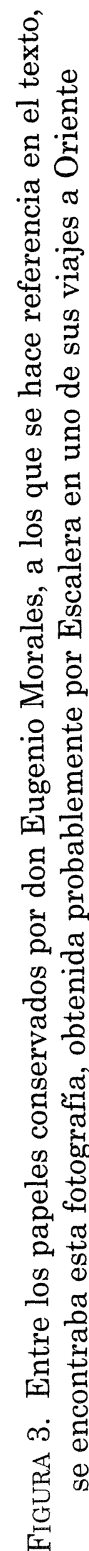


La fragilidad de la situación profesional de Escalera se reveló en todo caso tras la guerra Civil. Cuando en 1939, con Bolívar y buena parte de su equipo en el exilio, llegaron las nuevas autoridades al Museo, estas no prestaron ningún apoyo a un Escalera ya anciano, a pesar de no haberse significado políticamente durante la contienda. Olvidado por la ciencia oficial, murió el 8 de agosto de 1949 en Tánger, donde había pasado sus últimos años en compañía de su hija Emma. A ella se deben algunas notas que retratan al científico en la intimidad familiar y sobre todo en el campo, su natural elemento, despreocupado de todo cuanto no fueran sus insectos y más aun de su aspecto personal, calificado cariñosamente de «lamentable» ${ }^{24}$.

«[...] un trajecillo de dril y cubriendo su cabellera rojo azafrán un sombrerillo de tela. En la mano un mariposero y en banderola unos tubos y otros trebejos...»

\section{Notas}

1 Sociedad Española de Historia Natural (1899), p. 162.

2 OSBORNE (1994), RABY (1997), DRIVER (2001).

${ }^{3}$ ABIR-AM y ELLIOTT (1999).

${ }^{4}$ BARREIRO (1992), p. 304.

5 DUSMET y Alonso (1944), p. 28.

${ }^{6}$ GOMis Blanco (1996), p. 236.

7 CASADO (1998).

8 ALLEN (1976).

9 Martínez De la Escalera (1900): Examen del grupo Bathyscice de España.

10 CAMBEFoRT (2004).

11 [MARTínEZ DE LA ESCALERA] (sin fecha): Recuerdos de viaje y caza[.] Akbés y el Amanus 1898.

${ }^{12}$ Martínez de la EsCalera (1898).

13 Ibid.

${ }^{14}$ MARTÍNEZ DE LA ESCALERA (1900): [Nota sobre viaje a las provincias Sudoccidentales de la Persia.]

${ }^{15}$ [MARTínEZ DE LA EsCALERA] (sin fecha): Recuerdos de viaje y caza de un naturalista español[.] De Alepo á Bagdag.

16 Petituean, Jami y Moulin (1992), McLeod (2000).

17 González BuENo y Gomis Blanco (2001).

18 MARTínEZ DE LA ESCALERA (1914).

19 [MARTÍNEZ DE LA ESCALERA] (sin fecha): [Notas sobre película sobre los Baktiaris.]

${ }^{20}$ MacDougall (1978).

${ }^{21}$ [MARTÍNEZ DE LA ESCALERA] (sin fecha): [Notas sobre película sobre los Baktiaris.]

${ }^{22}$ Ibid.

${ }^{23}$ Bolívar y UrRutia (1915), p. 43.

${ }^{24}$ [MARTíNEZ DE LA ESCALERA, E.] ([1952]). 


\section{Manuel Martínez de la Escalera, ciencia y aventura en Oriente}

\section{Referencias bibliográficas}

ABIR-AM, P.G. y ELLIOTT, C. A., editores (1999): Conmemorative Practices in Science: Historical Perspectives on the Politics of Collective Memory (Osiris 14). University of Chicago Press, Chicago.

ALlen, D. E. (1976): The Naturalist in Britain. A Social History. Penguin, London.

BARREIRo, A. J. (1992): El Museo Nacional de Ciencias Naturales (1771-1935). Doce Calles, Aranjuez (Madrid). [Obra de 1936, no publicada íntegramente hasta 1992.]

Bolívar y URRUTIA, I. (1915): Discurso leído ante la Real Academia de Ciencias Exactas, Físicas y Naturales en su recepción pública por el Ilmo. Sr. D. Ignacio Bolívar y Urrutia. Real Academia de Ciencias Exactas, Físicas y Naturales, Madrid.

CAMBEFoRT, Y. (2004): René Oberthür (1852-1944) et sa collection. Le Coléopterologiste 7 (2), 111-115.

CASAdo, S. (1998): Rumbo a Oriente con Manuel Martínez de la Escalera. Quercus 151, 41-45.

DRIVER, F. (2001): Geography Militant: Cultures of Exploration and Empire. Blackwell, Oxford.

DUSMET y ALONSo, J.M. (1944): Discurso leído en el acto de su recepción por el Excmo. Sr. D. José $\mathrm{M}^{\mathrm{a}}$ Dusmet y Alonso. Real Academia de Ciencias Exactas, Físicas y Naturales, Madrid.

Gomis BlanCO, A. (1996): Real Sociedad Española de Historia Natural. Mundo Científico $166,228-239$.

GONZÁLEZ BuENO, A. y Goms BlaNCO, A. (2001): Los naturalistas españoles en el África Hispana (1860-1936). Organismo Autónomo Parques Nacionales, Madrid.

MacDougall, D. (1978): Ethnographic film: Failure and promise. Annual Review of Anthropology 7, 405-425.

[MARTÍNEZ DE LA ESCALERA, E.] ([1952]): [Notas biográficas sobre Manuel Martínez de la Escalera.] Mecanoscrito, $6 \mathrm{pp}$.

[MARTÍNEZ DE LA ESCALERA, M.] (sin fecha): Recuerdos de viaje y caza[.] Akbés y el Amanus 1898. Manuscrito, 5 pp.

[MARTÍNEZ DE LA ESCALERA, M.] (sin fecha): Recuerdos de viaje y caza de un naturalista español[.] De Alepo á Bagdag. Manuscrito, 3 pp.

[MARTínEZ DE LA EsCALERA, M.] (sin fecha): [Notas sobre película sobre los Baktiaris.] Manuscrito, $4 \mathrm{pp}$.

MARTÍNEZ DE LA ESCALERA, [M.] (1898): [Nota sobre expedición entomológica al Asia Menor]. Anales de la Sociedad Española de Historia Natural 27 (Actas), 150-151.

MARTínEZ DE LA EsCALERA, M. (1900): Examen del grupo Bathyscioe de España. Anales de la Sociedad Española de Historia Natural 28, 363-412.

MARTÍNEZ DE LA ESCALERA, [M.] (1900). [Nota sobre viaje a las provincias Sudoccidentales de la Persia]. Anales de la Sociedad Española de Historia Natural 29 (Actas), 72-75.

MARTÍNEZ DE LA EsCALERA, M. (1914): Los Coleópteros de Marruecos (Trabajos del Museo Nacional de Ciencias Naturales, Serie Zoológica 11). Museo Nacional de Ciencias Naturales, Madrid

MCLEOD, R., editor (2000): Nature and Empire: Science and the Colonial Enterprise (Osiris 15). University of Chicago Press, Chicago.

Osborne, M. A. (1994): Nature, the Exotic, and the Science of French Colonialism. Indiana University Press, Bloomington. 


\section{Santos Casado}

858

Petitjean, P., JAMI, C. y Moulin, A. M., editores (1992): Science and Empires. Kluwer, Dordrecht.

RABY, P. (1997): Bright paradise. Victorian scientific travellers. Princeton University Press, Princeton.

SocIEDAD ESPAÑola DE Historia NATURAL (1899): Sesión del 7 de Junio de 1899. Anales de la Sociedad Española de Historia Natural 28 (Actas), 161-164. 